\title{
Review Article \\ Recent Advances as Materials of Functional Metal-Organic Frameworks
}

\author{
Xiao-Lan Tong, ${ }^{1,2}$ Hai-Lu Lin, ${ }^{1}$ Jian-Hua Xin, ${ }^{1}$ Fen Liu, ${ }^{1}$ Min Li, ${ }^{1}$ and Xia-Ping Zhu ${ }^{1}$ \\ ${ }^{1}$ College of Biology, Chemistry and Material Science, East China Institute of Technology, Fuzhou, Jiangxi 344000, China \\ ${ }^{2}$ Fundamental Science on Radioactive Geology and Exploration Technology Laboratory, East China Institute of Technology, \\ NanChang, Jiangxi 330013, China
}

Correspondence should be addressed to Xiao-Lan Tong; xltongecit@163.com

Received 30 January 2013; Accepted 22 March 2013

Academic Editor: Jianmin Ma

Copyright (C) 2013 Xiao-Lan Tong et al. This is an open access article distributed under the Creative Commons Attribution License, which permits unrestricted use, distribution, and reproduction in any medium, provided the original work is properly cited.

\begin{abstract}
Metal-organic frameworks (MOFs), also known as hybrid inorganic-organic materials, represent an emerging class of materials that have attracted the imagination of solid-state chemists because MOFs combine unprecedented levels of porosity with a range of other functional properties that occur through the metal moiety and/or the organic ligand. The purpose of this critical review is to give a representative and comprehensive overview of the arising developments in the field of functional metal-organic frameworks, including luminescence, magnetism, and porosity through presenting examples. This review will be of interest to researchers and synthetic chemists attempting to design multifunctional MOFs.
\end{abstract}

\section{Introduction}

Metal organic frameworks (MOFs) are a new class of crystalline materials [1], the structures of which are composed of metal-oxide units or metal ions joined by organic linkers through strong covalent bonds. It may be defined as supramolecular solids but consists of strong bonding providing robustness, linking units that are available for modification by organic synthesis, and a geometrically well-defined structure. The latter property further implies that these solids should be highly crystalline. Specifically, the chemistry of MOFs has provided an extensive class of crystalline materials with high stability, tunable metrics, organic functionality, and porosity.

An extensive body of research results [2] currently exists from the synthesis of metal-organic frameworks (MOFs), an area that has attracted widespread attention due to the facility with which well-defined molecular building blocks can be assembled into periodic frameworks and the promise that such a process holds for the logical design of materials. The synthesis of MOFs generally involves the copolymerization of organic links and metal ions in a polar solvent under mild temperatures (up to $200^{\circ} \mathrm{C}$ ) and autogenous pressures (up to
$100 \mathrm{~atm})$. Since most products can be considered kinetically driven and lie on local thermodynamic minima, factors such as solubility of the organic link and metal salt, solvent polarity, ionic strength of the medium, temperature, and pressure play critical roles in determining the character of products. Indeed, slight perturbations in synthetic parameters have been the basis for the preparation of what seems to be a flood of new MOF compounds.

The designed construction of extended metal-organic frameworks from soluble molecular building blocks represent one of the most challenging issues facing synthetic chemistry today. Also metal-organic frameworks (MOFs) are widely studied because of their potential applications in many areas such as luminescence, magnetism, hydrogen storage, and gas adsorption and separation. We will give a representative and comprehensive overview of the arising developments of the functional MOFs.

\section{Luminescent Metal-Organic Frameworks}

The luminescent properties of metal-organic frameworks (MOFs) have attracted much attention for a long time, 


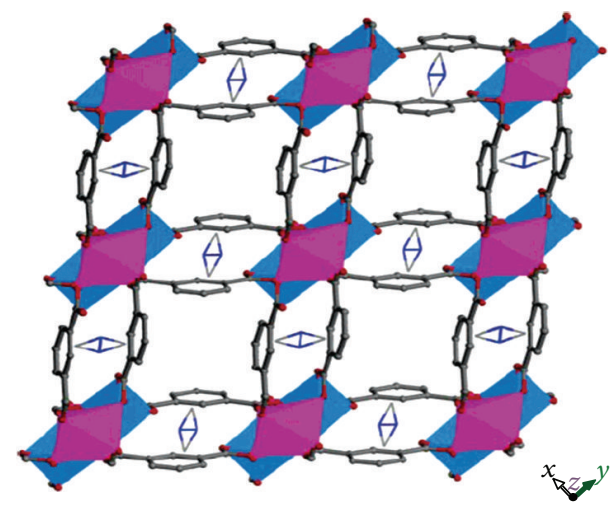

Figure 1: Framework of the MOF with DMF templating cations occupying the pores.

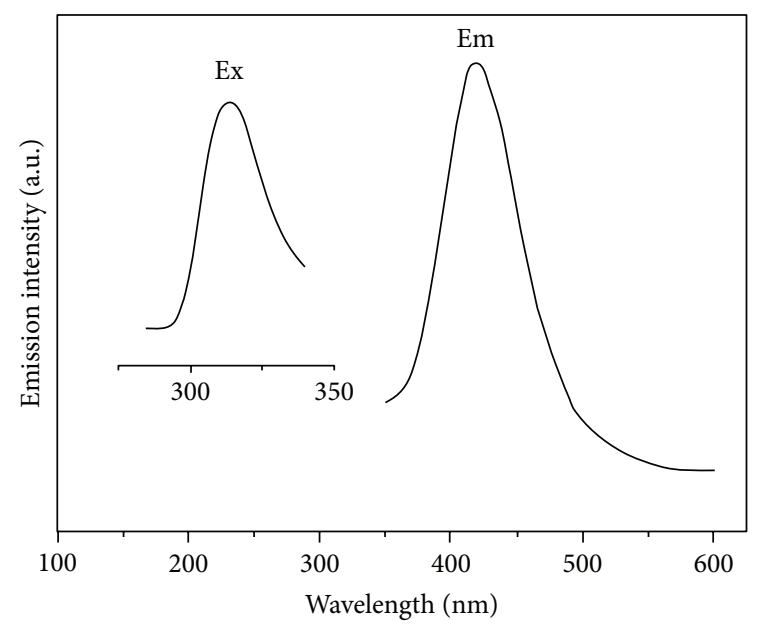

FIGURE 2: Photoluminescent spectrum of the MOF in the solid state at room temperature.

although these types of materials were frequently referred to as metal coordination polymers in the literature before the term "MOF" was widely adopted. The first report of luminescence, in which the structure was termed "MOF" that we are aware of, appeared in 2002. Since then, nearly 200 articles have appeared reporting light emission by MOFs, and a few reviews covering certain aspects of MOF luminescent properties have been published [3-10].

The hybrid nature of MOF materials, which include both an organic ligand and a metal ion, enables a wide range of emissive phenomena found in few other classes of material; the metal coordination can increase the conjugation and rigidity of the linkers. MOFs offer a unique platform for the development of solid-state luminescent materials as they have a degree of structural predictability, in addition to welldefined environments for lumophore in crystalline form. The lanthanoid (Ln) ions have spectrally narrow emission, even in solution, and nearly all of the lanthanoids exhibit photoluminescent properties [11-17].

$\mathrm{He}$ et al. [18] synthesized the first open-framework heterometallic MOF structure (Figure 1) based on the assembly

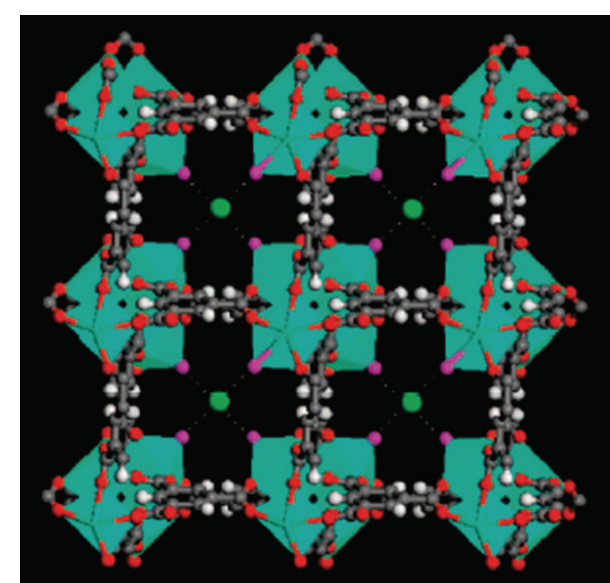

FIGURE 3: Single crystal X-ray structure of MOF-76b activated in methanol containing $\mathrm{NaF}$.

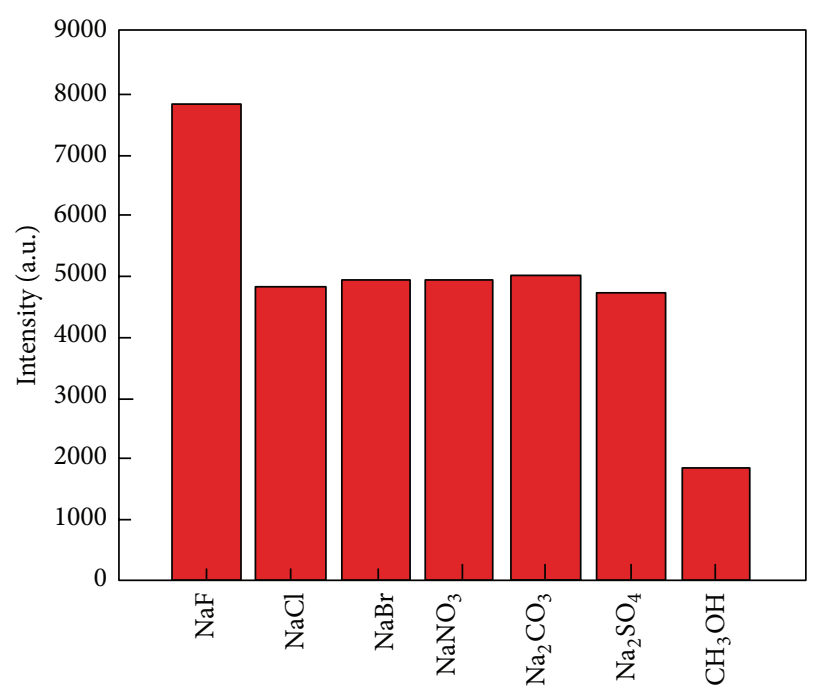

FIgURE $4:{ }^{5} \mathrm{D}_{4} \rightarrow{ }^{7} \mathrm{~F}_{5}$ transition intensities of MOF-76b activated in different types of 10-2 $M$ NaX and $\mathrm{Na} 2 \mathrm{X}$ methanol solution.

of infinite rod building units from the solvothermal reaction of zinc nitrate hexahydrate, sodium hydroxide, and 1,3benzene-dicarboxylic (m-BDC) acid. The strong fluorescent emission (Figure 2) of the above MOF may make it a potential useful photoactive material.

Chen et al. [19] report a prototype luminescent MOF (Figure 3), Tb (BTC).G (MOF-76: BTC = benzene-1,3,5tricarboxylate, $\mathrm{G}=$ guest solvent), for the recognition and sensing of anions, exhibiting a high-sensitivity sensing function with respect to fluoride (Figure 4). Such a recognition event can be readily transformed into an external luminescence intensity change once luminescent metal site and/or organic linkers have been incorporated into the luminescent MOFs.

\section{Magnetic Metal-Organic Frameworks}

One of the many interesting properties of metal-organic frameworks (MOF) is magnetism [20-22]. It can be implemented by incorporating magnetic moment carriers such 


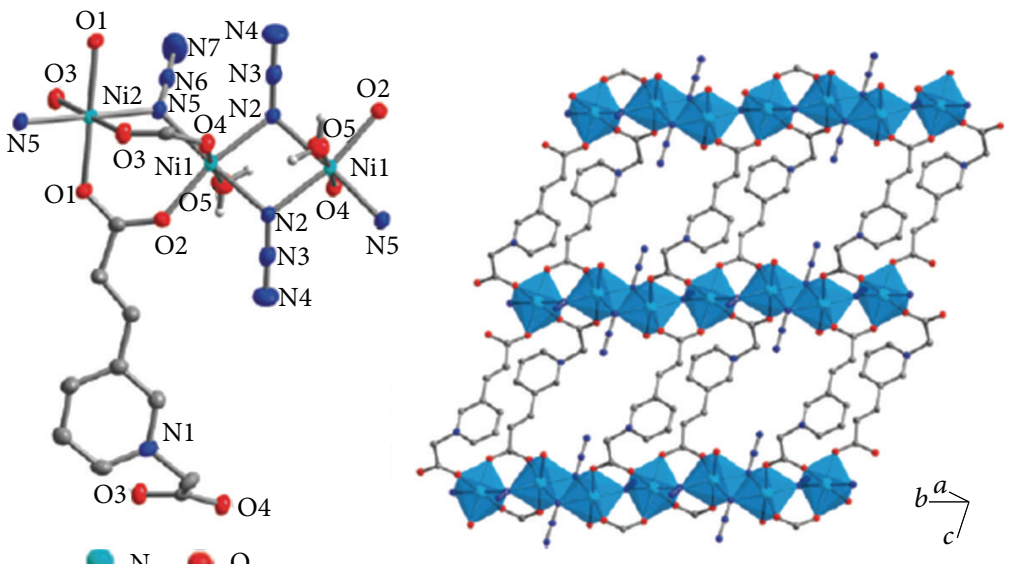

(a)

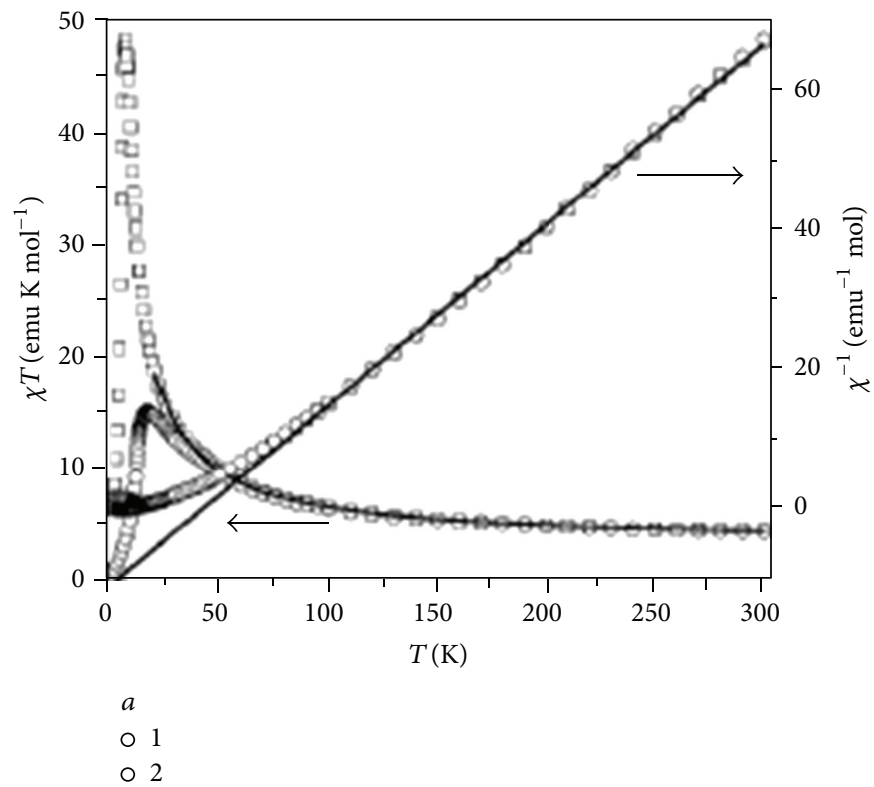

(b)

Figure 5: (a) The repeating unit (left) and the 2D layer formed by organic ligands interlinking $1 \mathrm{D}$ chains (right) in 1 . (b) The $\chi T$ and $1 /$ versus $\chi T$ plots at $1 \mathrm{kOe}$ for 1 and 2 .

as paramagnetic metals, open-shell organic ligands or both $[23,24]$. Magnetic MOFs and molecular magnets reported with their designs, synthetic approaches, structures, and physical properties [25-33] are both branches of coordination chemistry where metals are bound in a solid by coordination bonds to organic linkers. There exist several reviews dealing with the different aspects of magnetism [34-38].

Lanthanoid metals are attractive as magnetic materials because of their high spin numbers and strong magnetic anisotropies on the $4 \mathrm{f}$ orbitals. Magnetic materials based on lanthanoid metals or lanthanoid metal oxides have extensive applications [39-42].

Sun et al. [43] have reported a novel 2D coordination polymer 1 (Figure 5(a)) consisting of ferromagnetic Ni(II) chain with alternating double EO-azide bridges and (EOazide)bis(carboxylate) triple bridges, and the material exhibits solvent sensitive metamagnetism; it can become 2 by dehydrating. The reversible dehydration/hydration processes are accompanied by significant changes in critical temperature, critical field and hysteresis (Figure 5(b)).

Liu et al. [44] have successfully synthesized a high nuclearity cubic cage involving $64 \mathrm{Fe}^{3+}$ ions (Figure 6), which displays strong antiferromagnetism (Figure 7). They also demonstrate that the combination of the small stereohindrance $\mathrm{HCOO}^{-}$and polypodal ligands can obtain high nuclearity magnetic clusters in order to explore their novel and interesting magnetism. 


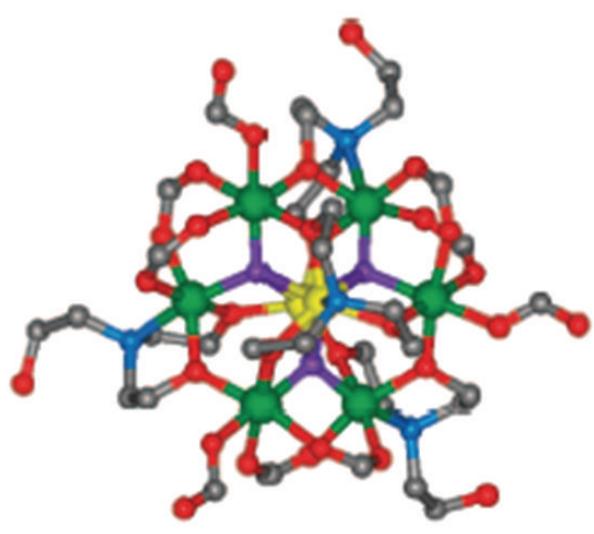

(a)

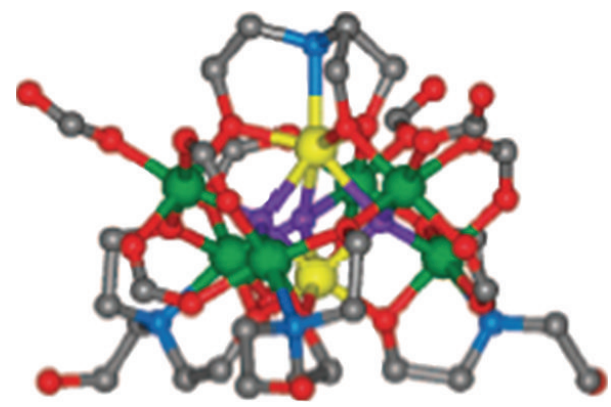

(b)

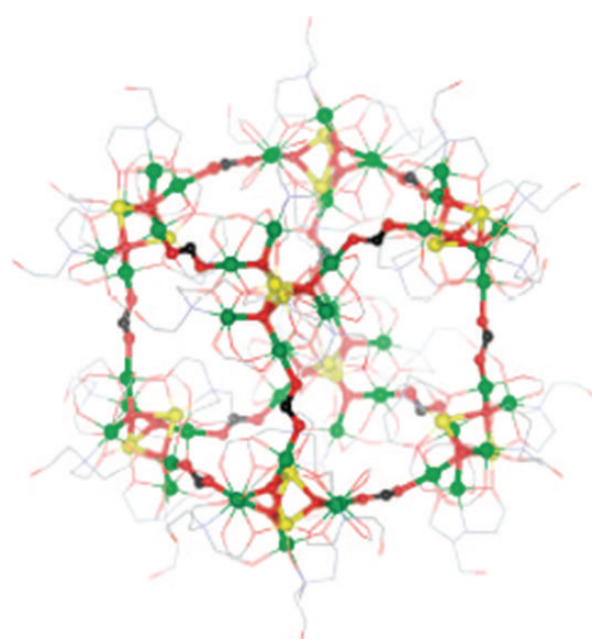

(c)

Figure 6: The structure of $\mathrm{Fe}_{64}$ cubic. ((a) and (b)) Top and side view of the $\mathrm{Fe}_{8}$ corner. (c) The cubic cage with the corner $\mathrm{Fe}_{8} \mathrm{O}_{3}$ cores and $\mathrm{HCOO}^{-}$edges highlighted.

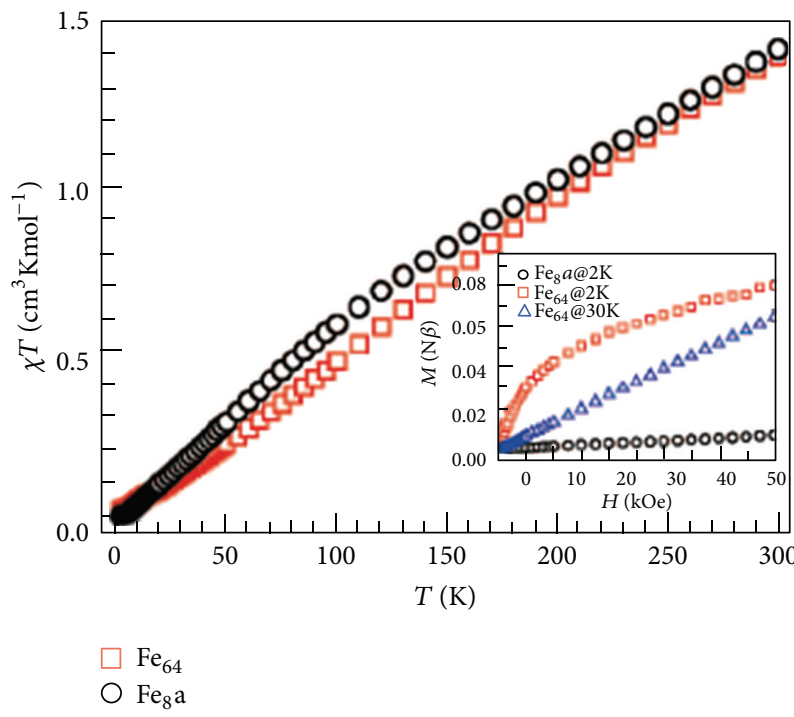

Figure 7: $\chi T$ versus $T$ plots under $1 \mathrm{KOe}$ field and $M$ versus $H$ plot (inset) for $\mathrm{Fe}_{64}$ and $\mathrm{Fe}_{8}$ a. Data are for one $\mathrm{Fe}^{3+}$.

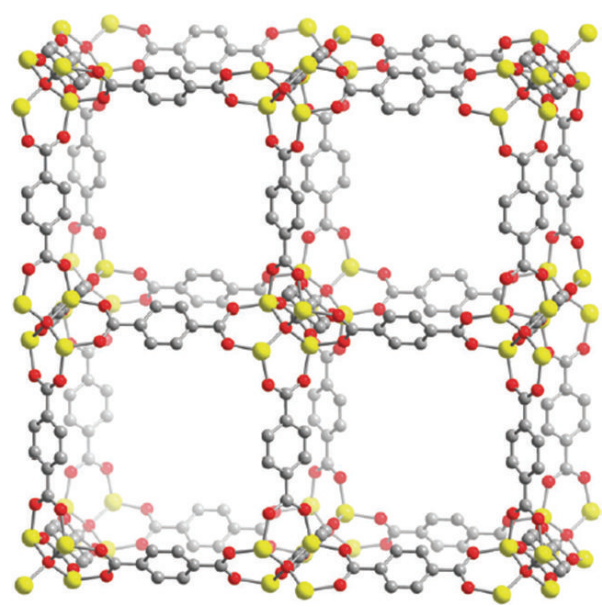

Figure 8: A portion of the crystal structure of $\mathrm{Zn}_{4} \mathrm{O}(\mathrm{BDC})_{3}$ (MOF-5). 


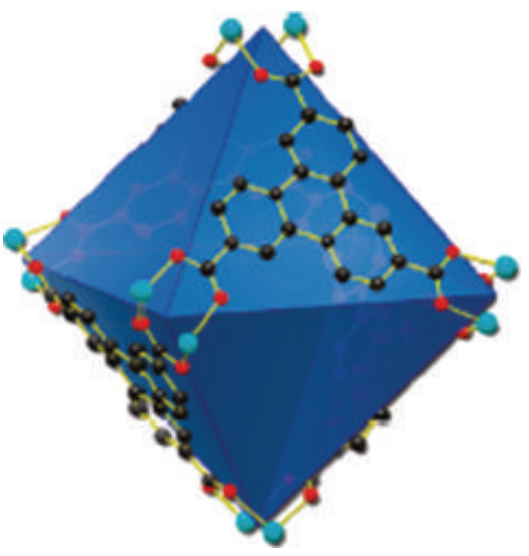

(a)

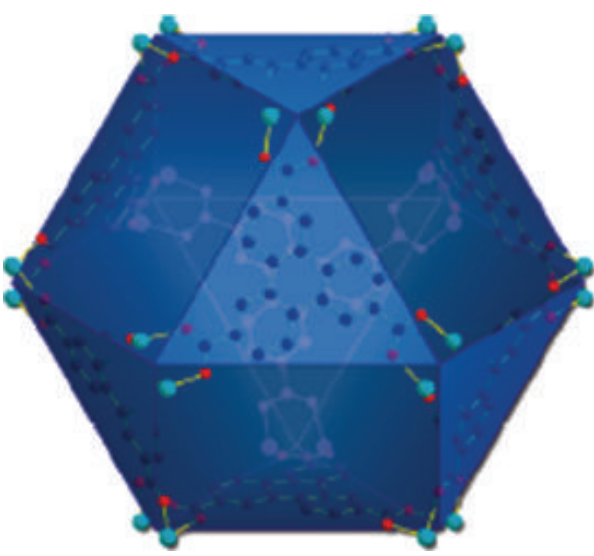

(b)

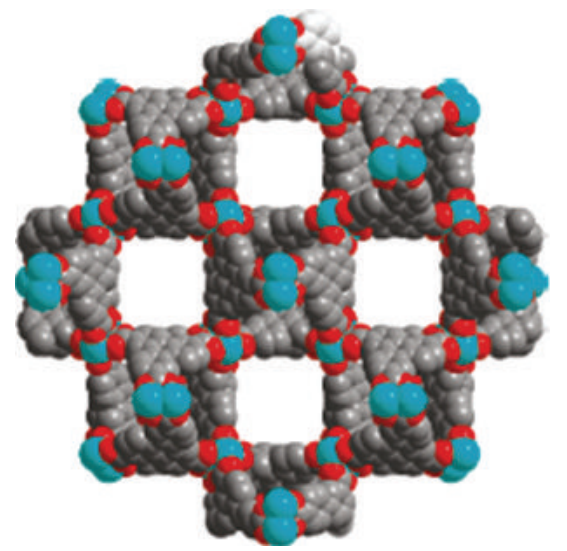

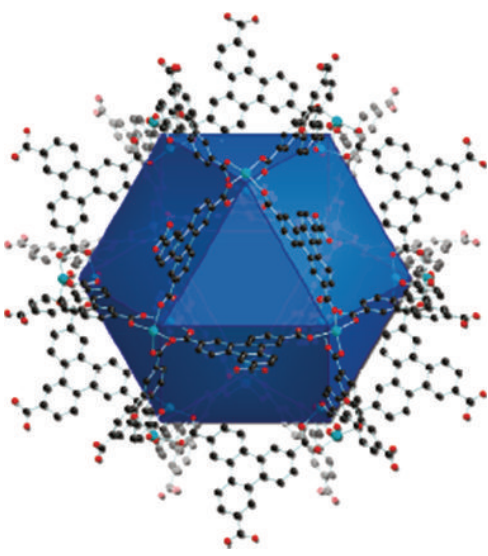

(c)

(d)

Figure 9: (a) Octahedral cage in PCN-20. (b) Cuboctahedral cage with alignment of the unsaturated metal center (UMCs) in PCN-20. (c) Cuboctahedral cage with open metal sites aligned orthogonally in PCN-20. (d) Square channels of PCN-20.

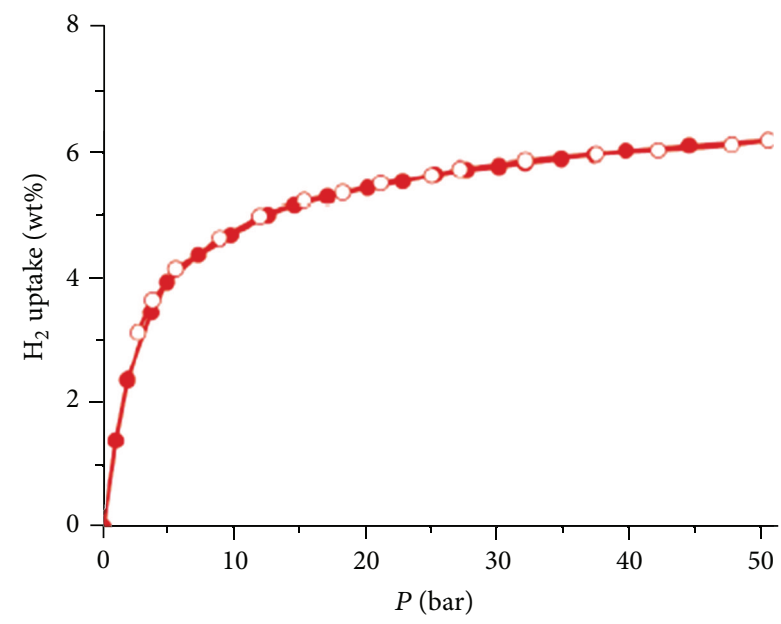

Figure 10: $\mathrm{H}_{2}$ sorption isotherms of PCN-20 at $77 \mathrm{~K}$, at high pressure.

\section{Porous Metal-Organic Frameworks}

The designed construction of extended porous frameworks from soluble molecular building blocks represents one of the most challenging issues facing synthetic chemistry today. A large number of wonders and advances have been made possible by the synthesis of porous metal-organic frameworks (MOFs) because they have a wide array of applications, ranging from hydrogen storage to gas adsorption and separation to catalysis and so on. Thanks to several effective engineering strategies, systematic fabrication of porous MOFs can be achieved through designer assembly from judiciously selected molecular building blocks.

4.1. Hydrogen Storage in Metal-Organic Frameworks. New materials capable of storing hydrogen at high gravimetric and volumetric densities are required if hydrogen is to be widely employed as a clean alternative to hydrocarbon fuels in cars and other mobile applications. With exceptionally high surface areas and chemical-tunable structures, microporous metal-organic frameworks have recently emerged as some of the most promising candidate materials; they can display outstanding performance characteristics for cryogenic hydrogen storage at $77 \mathrm{~K}$ and pressures up to $100 \mathrm{bar}$. 

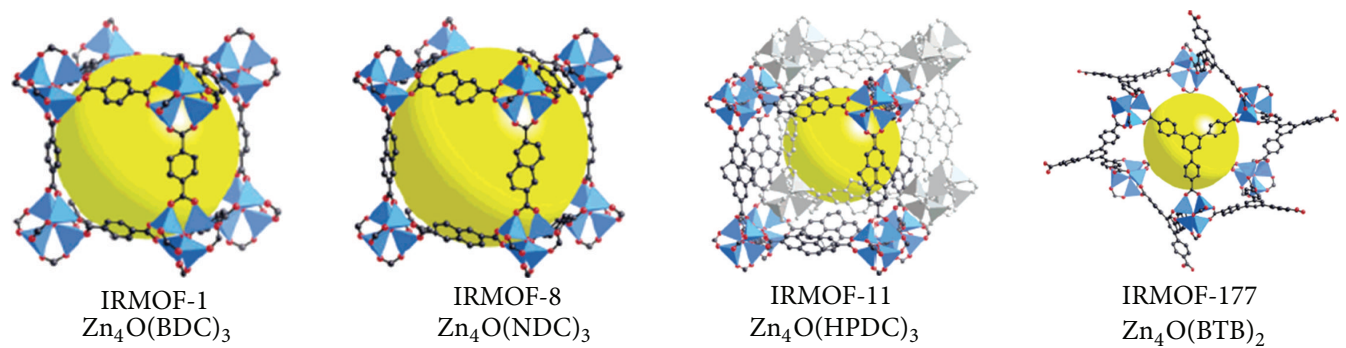

FIGURE 11: Metal-organic frameworks analyzed in this study.

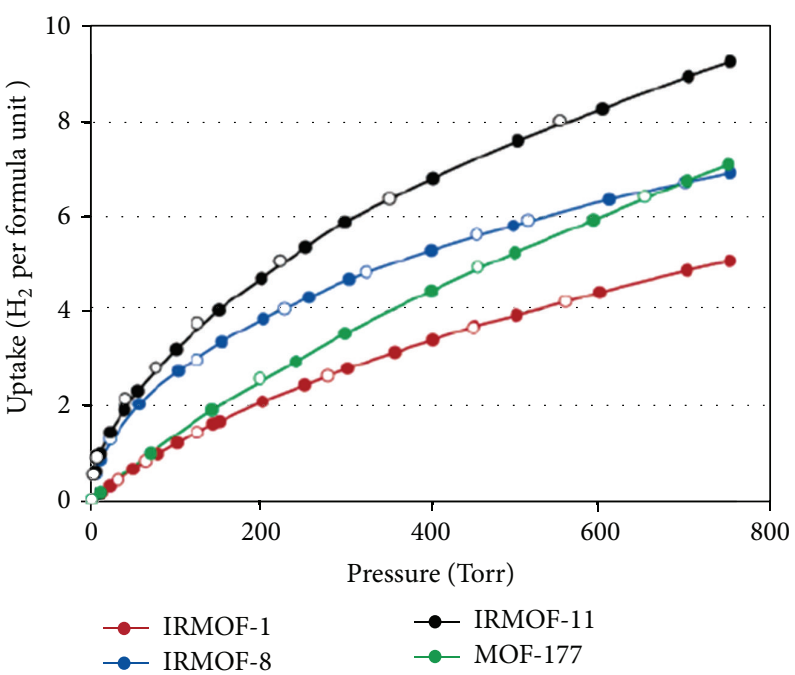

FIGURE 12: Hydrogen adsorption isotherms measured at $77 \mathrm{~K}$ for the MOFs analyzed in this study.

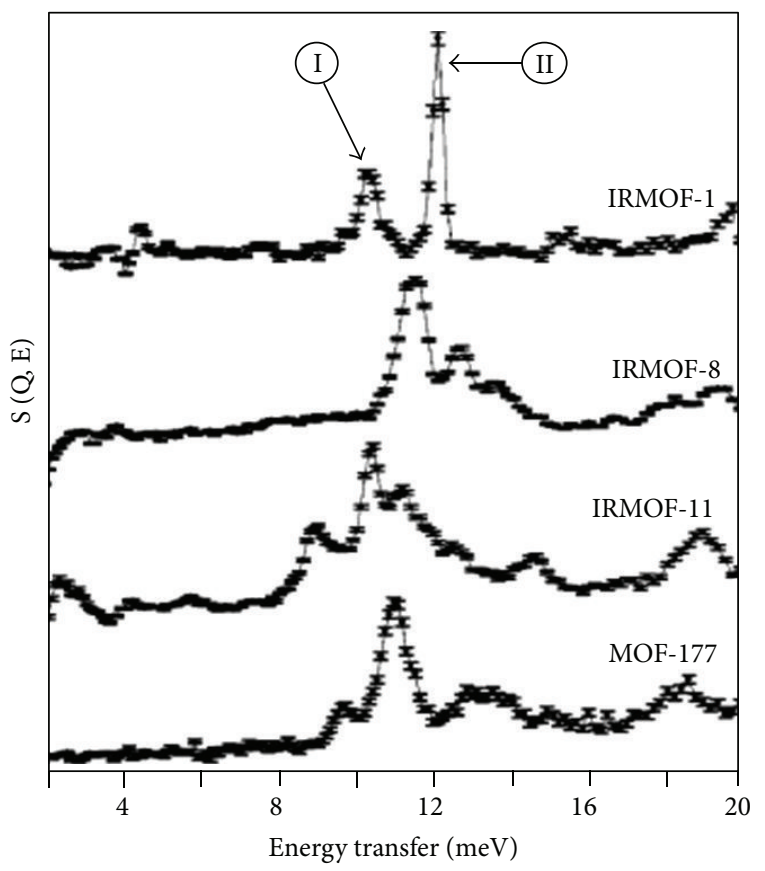

FIGURE 13: Inelastic neutron scattering spectra for each material loaded with $4 \mathrm{H}_{2}$ per formula unit.
One of the first metal-organic frameworks investigated for hydrogen storage was the cubic carboxylate-based framework $\mathrm{Zn}_{4} \mathrm{O}(\mathrm{BDC})_{3}$ (see Figure 8), and its gas storage properties were found to depend very large on the methods utilized in preparation and activation, with Langmuir surface areas ranging between 1010 and $4400 \mathrm{~m}^{2} \cdot \mathrm{g}^{-1}$ and $\mathrm{H}_{2}$ uptake capacity varying accordingly [45-49]. Inspired by the performance of compounds such as $\mathrm{Zn}_{4} \mathrm{O}(\mathrm{BDC})_{3}$, researchers have thus far reported hydrogen storage data for over 150 other microporous metal-organic frameworks [5055], containing carboxylate-based frameworks, heterocyclic azolate-based frameworks, mixed-ligand/functionality systems, metal cyanide frameworks, and so on.

Wang et al. [56] reported a porous MOF, PCN-20 (Figure 9) with a twisted boracite topology based on a designed planar TTCA ligand. PCN-20 possessed a large Langmuir surface area of over $4200 \mathrm{~m}^{2} \cdot \mathrm{g}^{-1}$ as well as demonstrated a high hydrogen uptake capacity of $6.2 \mathrm{wt} \%$ at $77 \mathrm{~K}$ and 50 bar (Figure 10).

Rowsell et al. [57, 58] have obtained remarkably detailed information on the primary binding sites of hydrogen in a series of metal-organic frameworks (Figures 11, 12, and 13) composed of $\mathrm{Zn}_{4} \mathrm{O}\left(\mathrm{O}_{2} \mathrm{C}\right)_{6}$ secondary building units with the use of inelastic neutron scattering from the hindered rotations of the adsorbed molecule. And this paper underlines the need to explore new topologies composed of novel secondary 


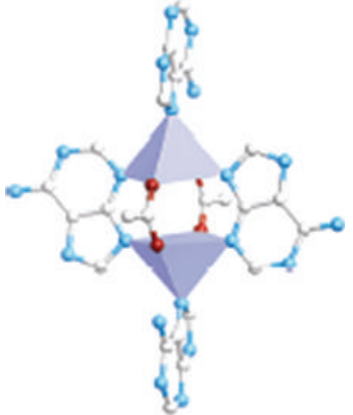

(a)

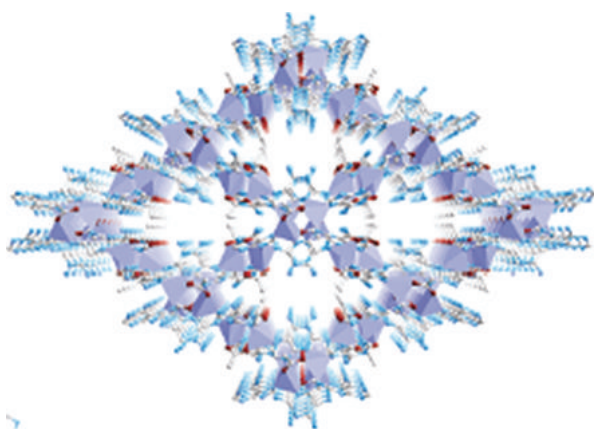

(b)

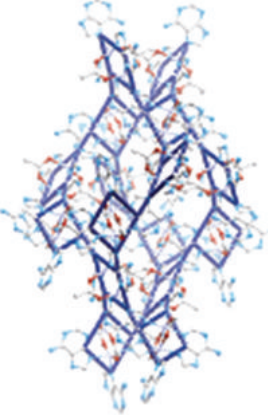

(c)

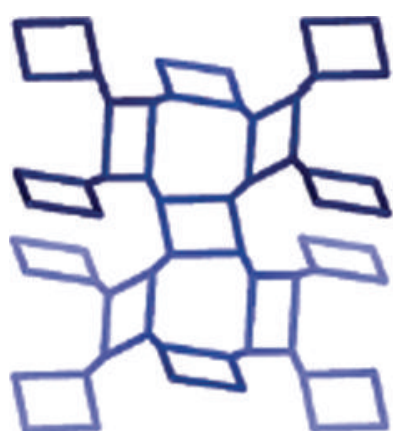

(d)

FIgURE 14: Crystal structure of bio-MOF-11.

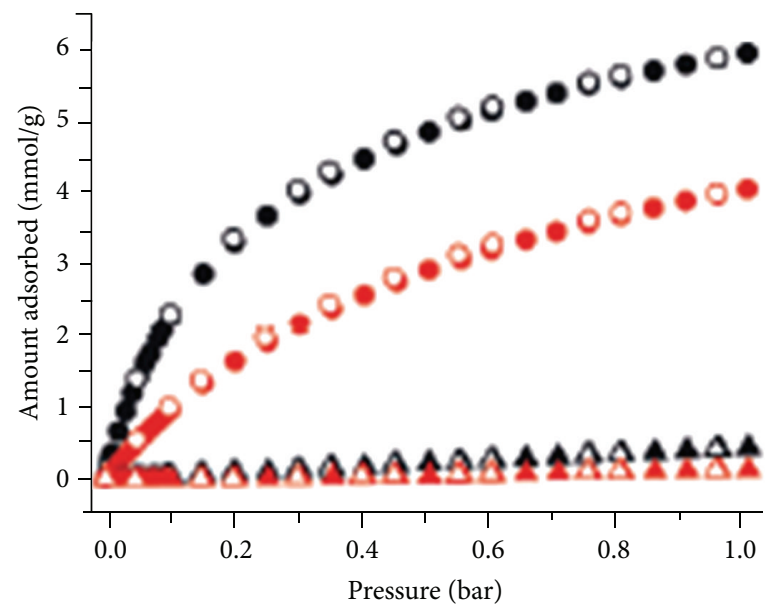

FIgURE 15: Adsorption isotherms for $\mathrm{CO}_{2}$ (circles) and $\mathrm{N}_{2}$ (triangles) at 273 (black) and $298 \mathrm{~K}$ (red).

building units from metal cations that have received less attention to increase the building energies for $\mathrm{H}_{2}$ on all sites. In particular, the use of more polarizing centers or the installment of open metal sites should enhance hydrogen physisorption by this case of materials.

However, significant further advances will be required in order to meet the US DoE targets for an onboard hydrogen system.

4.2. Gas Adsorption and Separation. In industry, the adsorptive separation needs efficient porous materials. Preparing as traditional porous solid material, the porous metalorganic frameworks with tailored structures and tunable surface properties are becoming promising candidates for gas adsorption and separations, also they have commendable thermal stability, in most cases, these structures are robust enough to allow the removal of the included guest species resulting in permanent porosity, so MOFs are ideal for research and practical applications, such as in gas separation and purification as adsorbents [59-63].

An et al. [64] have prepared a porous MOFs $\mathrm{Co}_{2}(\mathrm{ad})_{2}\left(\mathrm{CO}_{2} \mathrm{CH}_{3}\right)_{2} \cdot \mathrm{DMF} \cdot 0.5 \mathrm{H}_{2} \mathrm{O}$ (bio-MOF-11) (Figure 14) via a solvothermal reaction between cobalt acetate tetrahydrate and adenine in DMF, which has a high heat of adsorption for $\mathrm{CO}_{2}$, high $\mathrm{CO}_{2}$ capacity, and impressive selectivity for $\mathrm{CO}_{2}$ over $\mathrm{N}_{2}$ (Figure 15).

In 2009, Britt et al. [65] reported that a known MOF, Mg-MOF-74 (Figures 16 and 17), with open magnesium sites, rivals competitive materials in $\mathrm{CO}_{2}$ capture, with $8.9 \mathrm{wt} . \%$ dynamic capacity, and undergoes facile $\mathrm{CO}_{2}$ release at significantly lower temperature, $80^{\circ} \mathrm{C}$. Mg-MOF-74 offers an excellent balance between dynamic capacity and regeneration. These results demonstrate the potential of MOFs with open metal sites as efficient $\mathrm{CO}_{2}$ capture media.

$\mathrm{Li}$ et al. [66] reported a novel three zeolite-like chiral guest-free MOF material (Figure 18), [ $\mathrm{Zn}(\mathrm{dtp})]\left(\mathrm{H}_{2} \mathrm{dtp}=2,3\right.$ di-1H-tetrazol-5-ylpyrazine), which has high thermal stability and permanent porosity. It exhibits rare gas-adsorption selectivity for $\mathrm{O}_{2}$ and $\mathrm{CO}_{2}$ over $\mathrm{N}_{2}$ gas (Figure 19), and could be useful in the separation of air.

Besides, MOFs also have some other properties that occur through the metal moiety and/or the organic ligand, such as catalysts [67], enantioselective catalysis [68], and applications in industry [69].

\section{Conclusions Remarks}

We exhibited the variety applications as materials of few MOFs here; in fact although a large number of MOFs have 


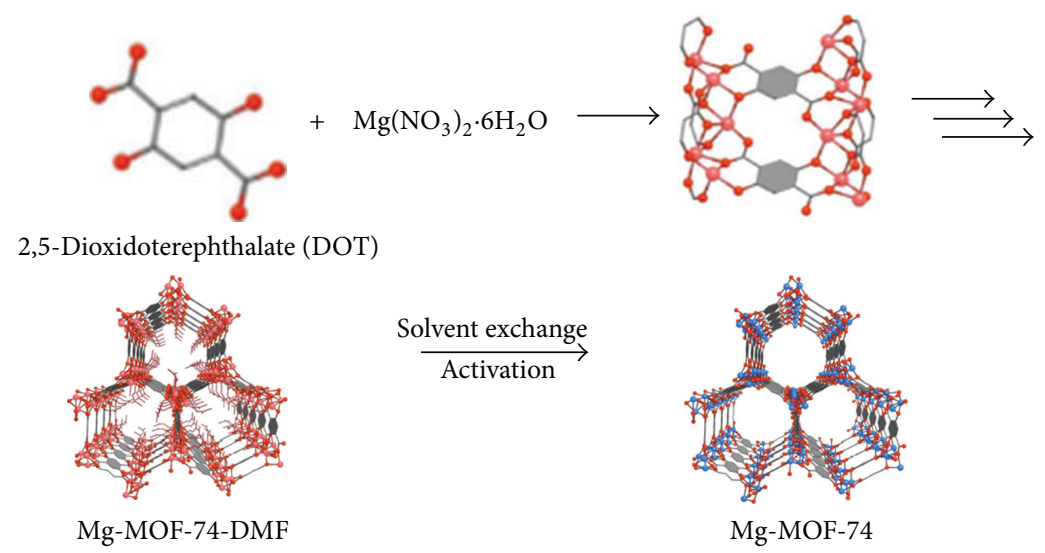

Figure 16: Single crystal structure of Mg-MOF-74.

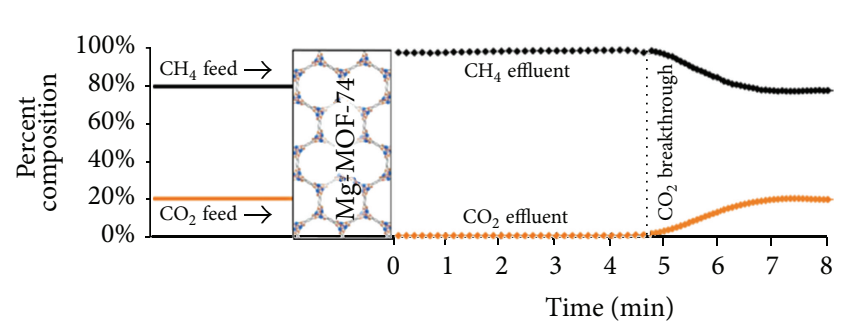

Figure 17: A 20\% mixture of $\mathrm{CO}_{2}$ in $\mathrm{CH}_{4}$ is fed into a bed of $\mathrm{Mg}$ MOF-74. Effluent concentrations are shown, indicating complete retention of $\mathrm{CO}_{2}$ until saturation. $\mathrm{CO}_{2}$ breakthrough occurs at the dashed line.

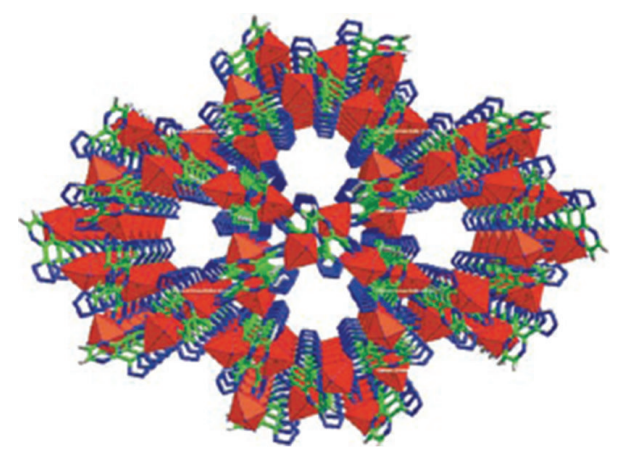

FIGURE 18: Structure of [ $\mathrm{Zn}(\mathrm{dtp})]$ showing open channel along the $c$ axis.

been reported until now, we only have seen the tip of the iceberg with respect to the application potential of MOFs. In order to investigate more potential applications of MOFs, an extensive body of researchers should pay for further effort.

\section{Acknowledgments}

This work was supported by Project of Jiangxi Provincial Department of Education (Grant no. GJJ12396 and no. GJJ11140), the open fund of Fundamental Science on Radioactive Geology and Exploration Technology Laboratory (REGT1212), the National Science Foundation of Jiangxi

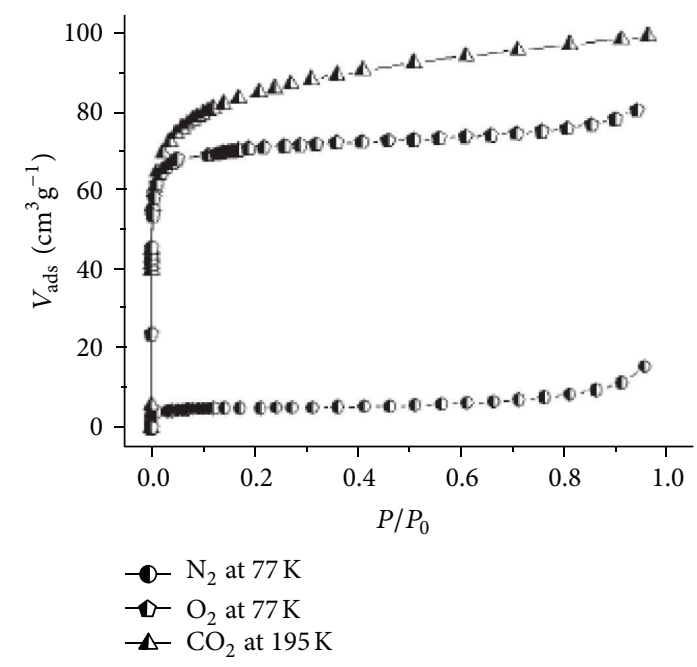

FIGURE 19: Adsorption isotherms of $\mathrm{N}_{2}, \mathrm{O}_{2}$ and $\mathrm{CO}_{2}$ for $[\mathrm{Zn}(\mathrm{dtp})]$.

Province (no. 2010GQH0007), and the Start-up Fund of East China Institute of Technology.

\section{References}

[1] D. Britt, D. Tranchemontagne, and O. M. Yaghi, "Metal-organic frameworks with high capacity and selectivity for harmful gases," Proceedings of the National Academy of Sciences of the United States of America, vol. 105, no. 33, pp. 11623-11627, 2008.

[2] N. L. Rosi, M. Eddaoudi, J. Kim, M. O'Keeffe, and O. M. Yaghi, "Advances in the chemistry of metal-organic frameworks," CrystEngComm, vol. 4, pp. 401-404, 2002.

[3] M. D. Allendorf, C. A. Bauer, R. K. Bhakta, and R. J. T. Houk, "Luminescent metal-organic frameworks," Chemical Society Reviews, vol. 38, no. 5, pp. 1330-1352, 2009.

[4] C. Janiak, "Engineering coordination polymers towards applications," Dalton Transactions, no. 14, pp. 2781-2804, 2003.

[5] C. L. Cahill, D. T. de Lill, and M. Frisch, "Homo- and heterometallic coordination polymers from the f elements," CrystEngComm, vol. 9, no. 1, pp. 15-26, 2007. 
[6] D. Maspoch, D. Ruiz-Molina, and J. Veciana, "Old materials with new tricks: multifunctional open-framework materials," Chemical Society Reviews, vol. 36, no. 5, pp. 770-818, 2007.

[7] T. Sakamoto, A. Ojida, and I. Hamachi, "Molecular recognition, fluorescence sensing, and biological assay of phosphate anion derivatives using artificial $\mathrm{Zn}$ (II)-Dpa complexes," Chemical Communications, no. 2, pp. 141-152, 2009.

[8] A. J. Moro, P. J. Cywinski, S. Körsten, and G. J. Mohr, "An ATP fluorescent chemosensor based on a $\mathrm{Zn}$ (II)-complexed dipicolylamine receptor coupled with a naphthalimide chromophore," Chemical Communications, no. 7, pp. 1085-1087, 2010.

[9] H. L. Jiang, Y. Tatsu, Z. H. Lu, and Q. Xu, "Non-, micro-, and mesoporous metal-organic framework isomers: reversible transformation, fluorescence sensing, and large molecule separation," Journal of the American Chemical Society, vol. 132, no. 16, pp. 5586-5587, 2010.

[10] M. Ji, X. Lan, Z. Ping, C. Hao, and J. Qiu, "Luminescent properties of metal-organic framework mof-5: relativistic timedependent density functional theory investigations," Inorganic Chemistry, vol. 51, no. 22, pp. 12389-12394, 2012.

[11] X. Q. Song, W. S. Liu, W. Don, Y. W. Wang, J. R. Zheng, and Z. P. Zang, "Structure variation and luminescence properties of lanthanide complexes incorporating a naphthalene-derived chromophore featuring salicylamide pendant arms," European Journal of Inorganic Chemistry, vol. 2008, no. 11, pp. 1901-1912, 2008.

[12] N. Sabbatini, M. Guardigli, and J. M. Lehn, "Luminescent lanthanide complexes as photochemical supramolecular devices," Coordination Chemistry Reviews, vol. 123, no. 1-2, pp. 201-228, 1993.

[13] F. S. Richardson, "Terbium(III) and europium(III) ions as luminescent probes and stains for biomolecular systems," Chemical Reviews, vol. 82, no. 5, pp. 541-552, 1982.

[14] B. D. Chandler, J. O. Yu, D. T. Cramb, and G. K. H. Shimizu, "Series of lanthanide-alkali metal-organic frameworks exhibiting luminescence and permanent microporosity," Chemistry of Materials, vol. 19, no. 18, pp. 4467-4473, 2007.

[15] P. Mahata and S. Natarajan, "A new series of threedimensional metal-organic framework, $\left[\begin{array}{ll}\mathrm{M}_{2} & \left(\mathrm{H}_{2} \mathrm{O}\right)\end{array}\right]$ $\left[\mathrm{C}_{5} \mathrm{~N}_{1} \mathrm{H}_{3}(\mathrm{COO})_{2}\right]_{3} \cdot 2 \mathrm{H}_{2} \mathrm{O}, \mathrm{M}=\mathrm{La}, \mathrm{Pr}$, and $\mathrm{Nd}$ : synthesis, structure, and properties," Inorganic Chemistry, vol. 46, no. 4, pp. 1250-1258, 2007.

[16] P. Mahata, K. V. Ramya, and S. Natarajan, "Synthesis, structure and optical properties of rare-earth benzene carboxylates," Dalton Transactions, no. 36, pp. 4017-4026, 2007.

[17] X. J. Zhang, Y. H. Xing, Z. Sun et al., "A series of twodimensional metal-organic frameworks based on the assembly of rigid and flexible carboxylate-containing mixed ligands with lanthanide metal salts," Crystal Growth \& Design, vol. 7, no. 10, pp. 2041-2046, 2007.

[18] J. He, J. Yu, Y. Zhang, Q. Pan, and R. Xu, "Synthesis, structure, and luminescent property of a heterometallic metal-organic framework constructed from rod-shaped secondary building blocks," Inorganic Chemistry, vol. 44, no. 25, pp. 9279-9282, 2005.

[19] B. Chen, L. Wang, F. Zapata, G. Qian, and E. B. Lobkovsky, "A luminescent microporous metal-organic framework for the recognition and sensing of anions," Journal of the American Chemical Society, vol. 130, no. 21, pp. 6718-6719, 2008.
[20] P. Day and A. E. Underhill, Eds., Metal-Organic and Organic Molecular Magnets, vol. 252, Royal Society of Chemistry, Cambridge, UK, 2000.

[21] C. N. R. Rao, A. K. Cheetham, and A. Thirumurugan, "Hybrid inorganic-organic materials: a new family in condensed matter physics," Journal of Physics: Condensed Matter, vol. 20, no. 8, Article ID 083202, 2008.

[22] M. Kurmoo, "Magnetic metal-organic frameworks," Chemical Society Reviews, vol. 38, pp. 1353-1379, 2009.

[23] S. J. Blundell and F. L. Pratt, "Organic and molecular magnets," Journal of Physics: Condensed Matter, vol. 16, no. 24, pp. R771R828, 2004.

[24] K. Itoh and M. Kinoshita, Eds., Molecular Magnetism: New Magnetic Materials, Gordon Breach-Kodansha, Tokyo, Japan, 2000.

[25] B. Moulton and M. J. Zaworotko, "From molecules to crystal engineering: supramolecular isomerism and polymorphism in network solids," Chemical Reviews, vol. 101, no. 6, pp. 1629-1658, 2001.

[26] M. E. Davis, "Ordered porous materials for emerging applications," Nature, vol. 417, no. 6891, pp. 813-821, 2002.

[27] C. Janiak, "Engineering coordination polymers towards applications," Dalton Transactions, no. 14, pp. 2781-2804, 2003.

[28] W. Lin, "Homochiral porous metal-organic frameworks: why and how?" Journal of Solid State Chemistry, vol. 178, no. 8, pp. 2486-2490, 2005.

[29] C. J. Kepert, "Advanced functional properties in nanoporous coordination framework materials," Chemical Communications, no. 7, pp. 695-700, 2006.

[30] D. Maspoch, D. Ruiz-Molina, and J. Veciana, "Old materials with new tricks: multifunctional open-framework materials," Chemical Society Reviews, vol. 36, no. 5, pp. 770-818, 2007.

[31] S. Chen, J. Zhang, and X. Bu, "Ionothermal synthesis of homochiral framework with acetate-pillared cobaltcamphorate architecture," Inorganic Chemistry, vol. 47, no. 13, pp. 5567-5569, 2008.

[32] Z. X. Li, J. P. Zhao, E. C. Saňudo et al., "New 3D coordination polymers constructed from pillared metal-formate kagome layers exhibiting spin canting only in the Nickel(II) complex," Inorganic Chemistry, vol. 48, no. 24, pp. 11601-11607, 2009.

[33] T. S. Venkatakrishnan, S. Sahoo, N. Bréfuel et al., "Enhanced ion anisotropy by nonconventional coordination geometry: singlechain magnet behavior for a $\left[\left\{\mathrm{Fe}^{\mathrm{II}} \mathrm{L}\right\}_{2}\left\{\mathrm{Nb}^{\mathrm{N}}(\mathrm{CN})_{8}\right\}\right]$ helical chain compound designed with heptacoordinate $\mathrm{Fe}^{\mathrm{II}}$," Journal of the American Chemical Society, vol. 132, no. 17, pp. 6047-6056, 2010.

[34] X. Y. Wang, Z. M. Wang, and S. Gao, "Constructing magnetic molecular solids by employing three-atom ligands as bridges," Chemical Communications, no. 3, pp. 281-294, 2008.

[35] N. Guillou, C. Livage, and G. Férey, "Cobalt and nickel oxide architectures in metal carboxylate frameworks: from coordination polymers to 3D inorganic skeletons," European Journal of Inorganic Chemistry, vol. 2006, no. 24, pp. 4963-4978, 2006.

[36] L. M. C. Beltran and J. R. Long, "Directed assembly of metalcyanide cluster magnets," Accounts of Chemical Research, vol. 38, no. 4, pp. 325-334, 2005.

[37] E. Coronado, C. Martí-Gastaldo, J. R. Galán-Mascarós, and M. Cavallini, "Polymetallic oxalate-based 2D magnets: soluble molecular precursors for the nanostructuration of magnetic oxides," Journal of the American Chemical Society, vol. 132, no. 15, pp. 5456-5468, 2010. 
[38] D. Sarma, P. Mahata, S. Natarajan, P. Panissod, G. Rogez, and M. Drillon, "Synthesis, structure, and magnetic properties of a new eight-connected metal-organic framework (MOF) based on $\mathrm{Co}_{4}$ clusters," Inorganic Chemistry, vol. 51, no. 8, pp. 44954501, 2012.

[39] K. Nakabayashi and S. Ohkoshi, "Monometallic lanthanoid assembly showing ferromagnetism with a Curie temperature of 11 K," Inorganic Chemistry, vol. 48, no. 18, pp. 8647-8649, 2009.

[40] X. Feng, L. Y. Wang, J. S. Zhao et al., "Series of aniondirected lanthanide-rigid-flexible frameworks: syntheses, structures, luminescence and magnetic properties," CrystEngComm, vol. 12, no. 3, pp. 774-783, 2010.

[41] Y. Wang, X. L. Li, T. W. Wang, Y. Song, and X. Z. You, "Slow relaxation processes and single-ion magnetic behaviors in dysprosium-containing complexes," Inorganic Chemistry, vol. 49, no. 3, pp. 969-976, 2010.

[42] D. P. Li, T. W. Wang, C. H. Li, D. S. Liu, Y. Z. Li, and X. Z. You, "Single-ion magnets based on mononuclear lanthanide complexes with chiral Schiff base ligands $\left[\operatorname{Ln}(\mathrm{FTA})_{3} \mathrm{~L}\right](\mathrm{Ln}=$ $\mathrm{Sm}, \mathrm{Eu}, \mathrm{Gd}, \mathrm{Tb}$ and Dy)," Chemical Communications, vol. 46, no. 17, pp. 2929-2931, 2010.

[43] W. W. Sun, C. Y. Tian, X. H. Jing, Y. Q. Wang, and E. Q. Gao, "Solvent-modulated metamagnetism in a nickel(II) coordination polymer with mixed azide and carboxylate bridges," Chemical Communications, no. 31, pp. 4741-4743, 2009.

[44] T. Liu, J. Zhang, Z. M. Wang, and S. Gao, "A 64-nuclear cubic cage incorporating propeller-like FeIII8 apices and HCOOedges," Journal of the American Chemical Society, vol. 130, no. 32, pp. 10500-10501, 2008.

[45] R. Q. Zhong, R. Q. Zou, M. Du et al., "Metal-organic frameworks of manganese(ii) 4,4/- biphenyldicarboxylates: crystal structures, hydrogen adsorption, and magnetism properties," CrystEngComm, vol. 12, no. 3, pp. 677-681, 2010.

[46] S. S. Kaye, A. Dailly, O. M. Yaghi, and J. R. Long, "Impact of preparation and handling on the hydrogen storage properties of $\mathrm{Zn}_{4} \mathrm{O}\left(1,4\right.$-benzenedicarboxylate) ${ }_{3}$ (MOF-5)," Journal of the American Chemical Society, vol. 129, no. 46, pp. 14176-14177, 2007.

[47] D. N. Dybtsev, H. Chun, and K. Kim, "Rigid and flexible: a highly porous metal-organic framework with unusual guestdependent dynamic behavior," Angewandte Chemie International Edition, vol. 43, no. 38, pp. 5033-5036, 2004.

[48] B. Panella and M. Hirscher, "Hydrogen physisorption in metalorganic porous crystals," Advanced Materials, vol. 17, no. 5, pp. 538-541, 2005.

[49] L. J. Murray, M. Dincă, and J. R. Long, "Hydrogen storage in metal-organic frameworks," Chemical Society Reviews, vol. 38, no. 5, pp. 1294-1314, 2009.

[50] S. S. Kaye and J. R. Long, "Hydrogen storage in the dehydrated prussian blue analogues $\mathrm{M}_{3}\left[\mathrm{Co}(\mathrm{CN})_{6}\right]_{2}(\mathrm{M}=\mathrm{Mn}, \mathrm{Fe}, \mathrm{Co}, \mathrm{Ni}$, $\mathrm{Cu}, \mathrm{Zn})$," Journal of the American Chemical Society, vol. 127, no. 18, pp. 6506-6507, 2005.

[51] F. Nouar, J. F. Eubank, T. Bousquet, L. Wojtas, M. J. Zaworotko, and M. Eddaoudi, "Supermolecular building blocks (SBBs) for the design and synthesis of highly porous metal-organic frameworks," Journal of the American Chemical Society, vol. 130, no. 6, pp. 1833-1835, 2008.

[52] I. Senkovska and S. Kaskel, "Solvent-Induced pore-size adjustment in the metal-organic framework $\left[\mathrm{Mg}_{3}(\mathrm{ndc})_{3}(\mathrm{dmf})_{4}\right]$ (ndc = naphthalenedicarboxylate)," European Journal of Inorganic Chemistry, vol. 2006, no. 22, pp. 4564-4569, 2006.
[53] M. Dincă and J. R. Long, "High-enthalpy hydrogen adsorption in cation-exchanged variants of the microporous metal-organic framework $\mathrm{Mn}_{3}\left[\left(\mathrm{Mn}_{4} \mathrm{Cl}\right)_{3}(\mathrm{BTT})_{8}\left(\mathrm{CH}_{3} \mathrm{OH}\right)_{10}\right]_{2}$," Journal of the American Chemical Society, vol. 129, no. 36, pp. 11172-11176, 2007.

[54] D. Sun, S. Ma, Y. ke, D. J. Collins, and H. C. Zhou, "An Interweaving MOF with high hydrogen uptake," Journal of the American Chemical Society, vol. 128, no. 12, pp. 3896-3897, 2006.

[55] R. Zou, A. I. Abdel-Fattah, H. Xu, Y. Zhao, and D. D. Hickmott, "Storage and separation applications of nanoporous metalorganic frameworks," CrystEngComm, vol. 12, no. 5, pp. 13371353, 2010.

[56] X. S. Wang, S. Ma, D. Yuan et al., "A large-surface-area boracitenetwork-topology porous MOF constructed from a conjugated ligand exhibiting a high hydrogen uptake capacity," Inorganic Chemistry, vol. 48, no. 16, pp. 7519-7521, 2009.

[57] J. L. C. Rowsell, J. Eckert, and O. M. Yaghi, "Characterization of $\mathrm{H}_{2}$ binding sites in prototypical metal-organic frameworks by inelastic neutron scattering," Journal of the American Chemical Society, vol. 127, no. 42, pp. 14904-14910, 2005.

[58] J. L. C. Rowsell, A. R. Millward, K. S. Park, and O. M. Yaghi, "Hydrogen sorption in functionalized metal-organic frameworks," Journal of the American Chemical Society, vol. 126, no. 18, pp. 5666-5667, 2004.

[59] U. Mueller, M. Schubert, F. Teich, H. Puetter, K. SchierleArndt, and J. Pastré, "Metal-organic frameworks-prospective industrial applications," Journal of Materials Chemistry, vol. 16, no. 7, pp. 626-636, 2006.

[60] D. Britt, D. Tranchemontagne, and O. M. Yaghi, "Metal-organic frameworks with high capacity and selectivity for harmful gases," Proceedings of the National Academy of Sciences of the United States of America, vol. 105, no. 33, pp. 11623-11627, 2008.

[61] L. H. Xie, J. B. Lin, X. M. Liu et al., "Porous coordination polymer with flexibility imparted by coordinatively changeable lithium ions on the pore surface," Inorganic Chemistry, vol. 49, no. 3, pp. 1158-1165, 2010.

[62] A. U. Czaja, N. Trukhan, and U. Mueller, "Industrial applications of metal-organic frameworks," Chemical Society Reviews, vol. 38, no. 5, pp. 1284-1293, 2009.

[63] S. J. Yang, T. Kim, J. H. Im et al., "MOF-derived hierarchically porous carbon with exceptional porosity and hydrogen storage capacity," Chemistry of Materials, vol. 24, no. 3, pp. 464-470, 2012.

[64] J. An, S. J. Geib, and N. L. Rosi, "High and selective $\mathrm{CO}_{2}$ uptake in a cobalt adeninate metal-organic framework exhibiting pyrimidine- and amino-decorated pores," Journal of the American Chemical Society, vol. 132, no. 1, pp. 38-39, 2010.

[65] D. Britt, H. Furukawa, B. Wang, T. G. Glover, and O. M. Yaghi, "Highly efficient separation of carbon dioxide by a metalorganic framework replete with open metal sites," Proceedings of the National Academy of Sciences of the United States of America, vol. 106, no. 49, pp. 20637-20640, 2009.

[66] J. R. Li, Y. Tao, Q. Yu, X. H. Bu, H. Sakamoto, and S. Kitagawa, "Selective gas adsorption and unique structural topology of a highly stable guest-free zeolite-type MOF material with N-rich chiral open channels," Chemistry - A European Journal, vol. 14, no. 9, pp. 2771-2776, 2008.

[67] J. Lee, O. K. Farha, J. Roberts, K. A. Scheidt, S. T. Nguyen, and J. T. Hupp, "Metal-organic framework materials as catalysts," Chemical Society Reviews, vol. 38, no. 5, pp. 1450-1459, 2009. 
[68] L. Ma, C. Abney, and W. Lin, "Enantioselective catalysis with homochiral metal-organic frameworks," Chemical Society Reviews, vol. 38, no. 5, pp. 1248-1256, 2009.

[69] A. U. Czaja, N. Trukhan, and U. Müller, "Industrial applications of metal-organic frameworks," Chemical Society Reviews, vol. 38, no. 5, pp. 1284-1293, 2009. 

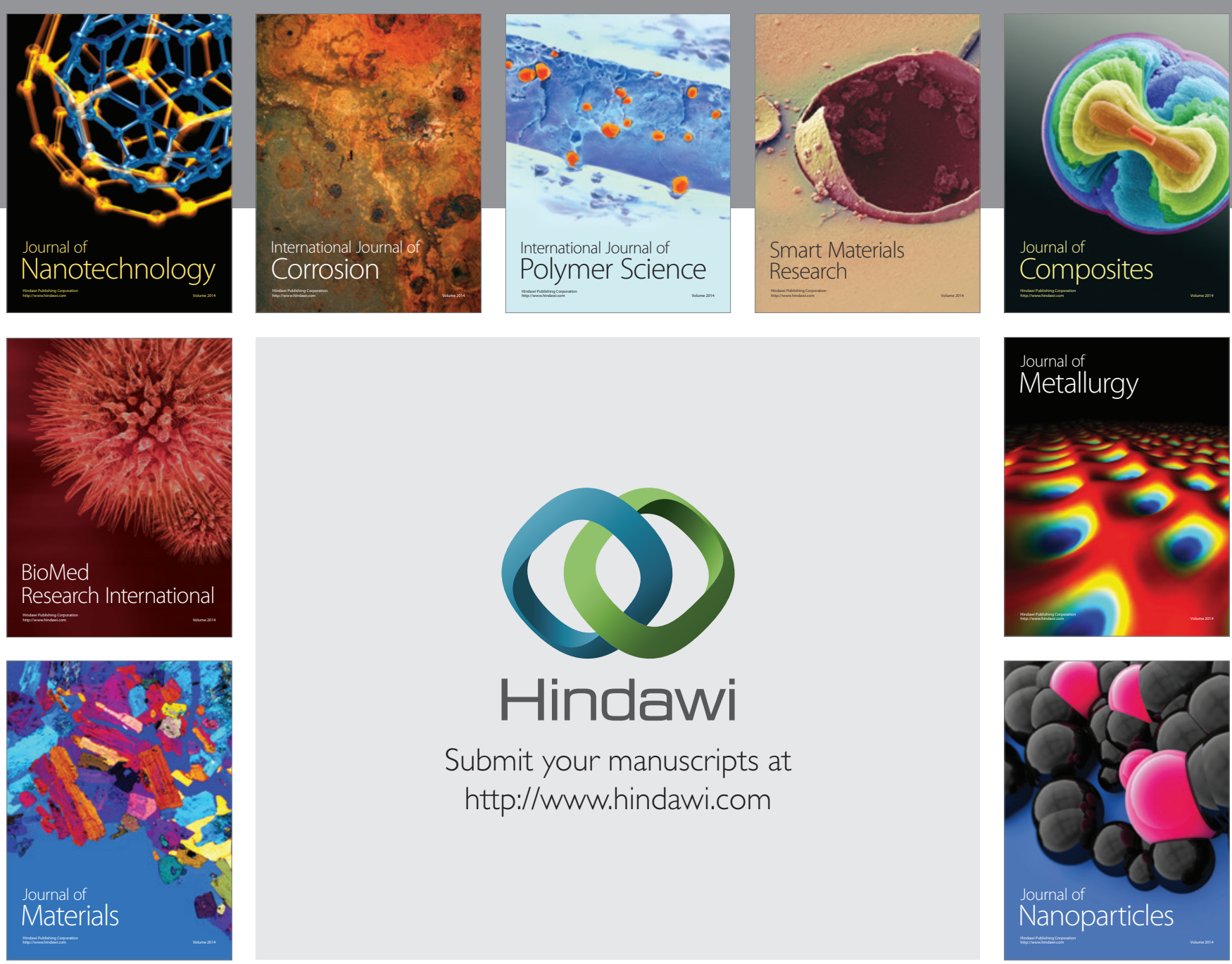

Submit your manuscripts at http://www.hindawi.com
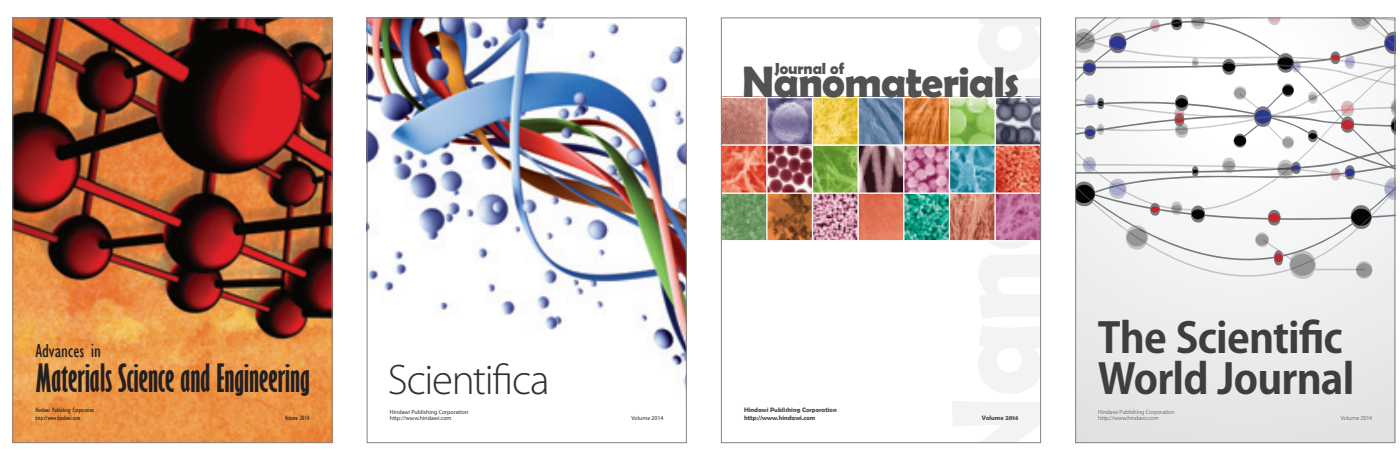

\section{The Scientific World Journal}
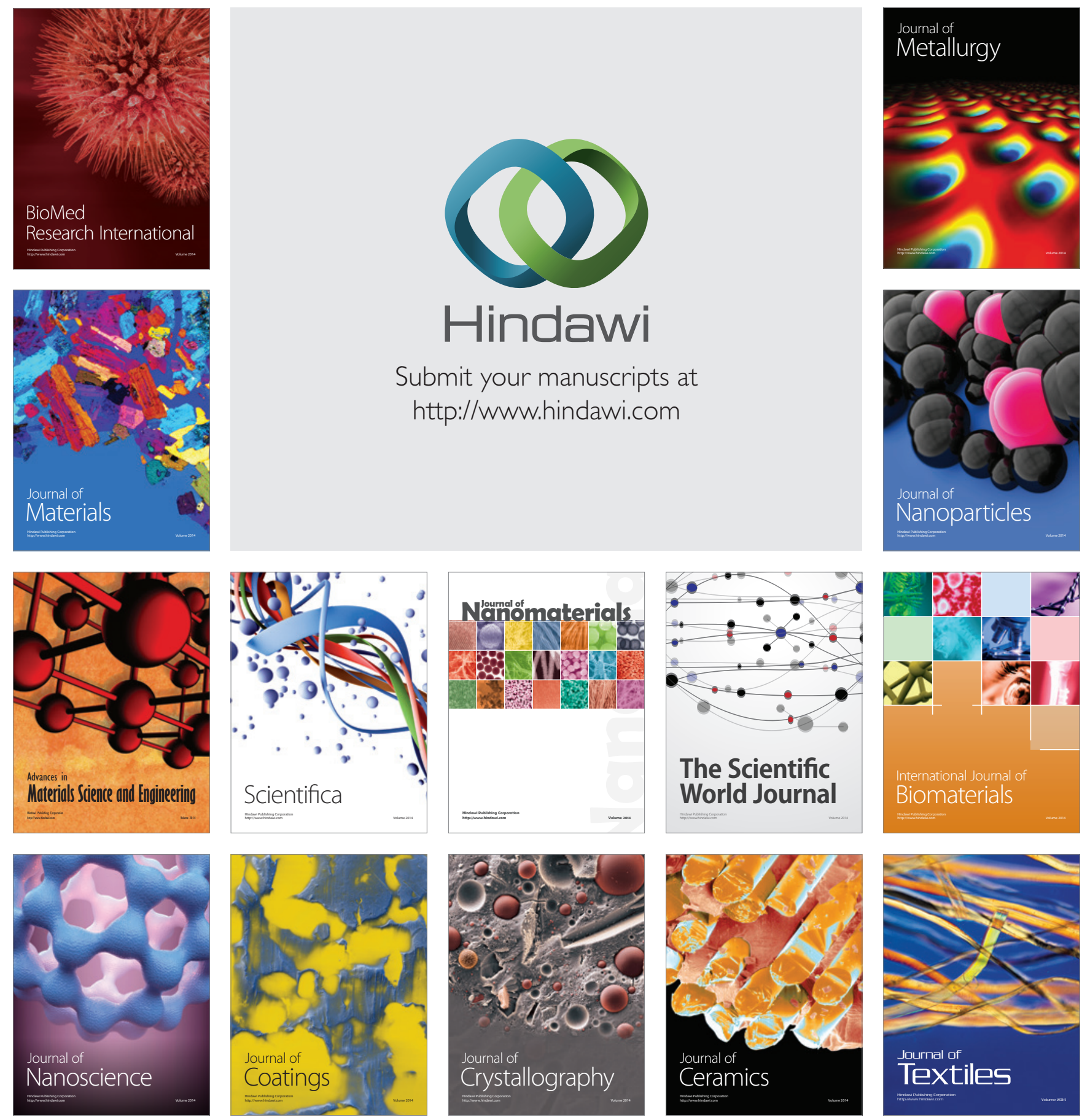